\title{
El populismo como \\ experimento político: \\ historia y teoría política \\ de una ambivalencia
}

\section{Raimundo Frei y Cristóbal Rovira Kaltwasser ${ }^{1}$}

\section{Resumen}

Una vez más el concepto de populismo se ha puesto de moda, lo cual se debe en parte a la irrupción de líderes como Chávez en Venezuela o Berlusconi en Italia. Sin embargo, las Ciencias Sociales tienen un problema serio para definir qué es el populismo y para elaborar una teoría política sobre este fenómeno. El presente artículo enfrenta este problema y para ello se divide en dos apartados. En primer lugar, se ofrece un análisis histórico del concepto de populismo que demuestra que dicho término ha sido utilizado para tematizar una serie de ambivalencias inmanentes a todo orden político. En segundo lugar, se elabora una definición típico ideal del populismo y se propone un esbozo de una teoría política de este fenómeno. La teoría propuesta trasciende la usual demonización o divinización del populismo, en cuanto desarrolla una perspectiva que ayuda a comprenderlo antes que a juzgarlo normativamente.

\section{Populism as a political experiment: the history and political theory of an ambivalence}

\begin{abstract}
Once again the concept of populism is en vogue, partly due to the fact that leaders such as Chávez in Venezuela and Berlusconi in Italy have come to power. However, the Social Sciences have serious problems in defining populism and elaborating a political theory to grasp this phenomenon. The present article attempts to fill this void. It is divided into two sections. The first part presents a historical analysis of the concept of populism, which demonstrates that it has been used to tackle a set of ambivalences immanent to all political order. The second part elaborates an idealtypical definition of populism and offers a theoretical outline of this phenomenon. The proposed theory transcends the demonisation or divinisation of populism; it offers a perspective that helps to comprehend rather than pass a normative judgment on the concept.
\end{abstract}

\footnotetext{
${ }^{1}$ Raimundo Frei es Sociólogo de la Universidad de Chile e investigador del Programa de las Naciones Unidas para el Desarrollo (raimundo.frei@undp.org). Cristóbal Rovira Kaltwasser es Sociólogo de la Universidad de Chile y Doctor en Ciencia Política de la Humboldt-Universität zu Berlin (rokaltwc@,cms.hu-berlin.de). Los autores quisieran agredecer los valiosos comentarios de Matthias Bohlender, Karsten Fischer, John Keane y Herfried Münkler, quienes no necesariamente comparten los argumentos vertidos en este documento ni son responsables de los posibles errores que éste pueda contener.
} 


\section{Desarrollo histórico del concepto de populismo en las Cien- cias Sociales}

La historia del concepto 'populismo' se podría condensar rápidamente en dos términos: imprecisión y ambivalencia. De hecho, uno de los consensos más importantes de cientistas políticos, historiadores y sociólogos que se han adentrado en este tema, es que el concepto tiene una dificultad inherente para ser definido con rigurosidad. Arditi se refiere a él como un objeto 'anexacto' por la fluidez de sus entornos (Arditi 2005: 79), Canovan ha dicho que es uno de los términos menos precisos del vocabulario de las ciencias políticas (1999: 446), Hermet ha hablado de una deficiencia teórica extrema como concepto (2003: 6), Laclau ha afirmado que la claridad analítica está visiblemente ausente en este campo (2005a: 15) y Vilas postula que el populismo como concepto ha perdido valor conceptual y se ha reducido a una simple adjetivación (1988: 233).

Observar el desarrollo histórico del concepto es comparable a la vista que ofrece una pista de hielo repleta de patinadores, algunos más expertos y otros más novatos, donde es dificil encontrar posiciones firmes y constantes en el tiempo. En esta historia conceptual, los permanentes intentos de redefinición, los numerosos análisis y congresos que se realizan año tras año en diversas partes del mundo, nos indican que la pista de hielo permanece abierta y llena de participantes durante la mayor parte del tiempo. En este sentido, sigue siendo válida la afirmación que Laclau realizó hace ya treinta años: pese a su indefinición, el populismo sigue gozando de buena salud en las Ciencias Sociales (1978: 169).

En consecuencia, no parece existir consenso alguno frente a qué es el populismo. ¿Se trata de una ideología, un movimiento social, un tipo de liderazgo o un régimen político? Una primera respuesta se puede obtener por medio de la etimología. El concepto mantiene cierta relación con el vocablo latín populus, el cual era ocupado en la tradición política de la Antigua Roma para la enunciación de la totalidad de la población de un Estado constituido (Taguieff 1996: 73). Sin embargo, cuando hoy en día se analiza el populismo no se describe la incorporación de todos los miembros de una comunidad en una totalidad, sino que más bien se señala la emergencia de una línea de separación al interior de la sociedad a partir de la cual se constituyen dos grupos antagónicos.

Otra etimología posible para entender el populismo puede ser hallada a partir de la suposición de que este concepto se deriva de la palabra latina plebs, la cual era utilizada en la antigua Roma para designar a los no patricios. En este caso, se trata de una categoría que diferencia al pueblo tanto de los nobles como de los esclavos, de manera tal que pese a su carácter peyorativo concede un relativo reconocimiento de derechos. De hecho, la palabra plebs asoma en el concepto de plebiscito, lo cual literalmente significa decisión del pueblo. Sin embargo, aún faltaría en este precedente 
el impulso a la representación total de la sociedad que todo populismo contiene; aquella apelación al pueblo como un todo o en palabras de Laclau, "una parcialidad que quiera funcionar como la totalidad de la comunidad" (2005a: 108).

Pero no solamente en su etimología se presenta la ambivalencia conceptual del populismo. Ésta se reproduce especialmente en dos campos: en la valoración (o rechazo) que se hace de él y en su posición dentro de las definiciones de los sistemas políticos. Como valoración, bien es conocida la afirmación que el populismo puede ser considerado como la enfermedad de los sistemas democráticos modernos, ya sea por su potencial tiránico y disruptivo de los derechos individuales o sino por su radicalización de los principios de soberanía popular, exhibiendo una de las formas más puras del orden democrático (Abts y Rummens 2007: 405)².

Respecto a la posición del populismo en el sistema político, éste transita continuamente en ser caracterizado como un régimen autoritario o uno democrático. Se le ha asociado con el fascismo (Di Tella 1993: 544, en Savarino 2006:10) y se le emparienta con el militarismo (Ramos 1988: 48), aunque también ha sido definido como compatible con la democracia en la medida que asegura el derecho de las mayorías (Worsley 1969: 302). Por ello, algunos han señalado su carácter híbrido, vale decir, que se sitúa en una zona gris entre un régimen autoritario y uno democrático (Germani 1965:336, Gratius 2007:1-4).Y aquellos que han afirmado que la problemática populista reside en el corazón de la democracia, han intentado ubicar al populismo en la tensión que se produce entre un modelo de democracia liberal y un modelo de democracia radical (Arditi 2005).

Nuestra propuesta intenta ir más allá de discusiones etimológicas y a su vez busca superar aquellas de definiciones del populismo que persiguen su valoración o rechazo así como también su categorización como régimen autoritario o democrático. Lo singular de la perspetiva que aquí se propone es que se define al populismo como un fenómeno constitutivo de la política que se cristaliza de diferentes modos a lo largo del tiempo. Desde este ángulo, resulta valioso hacer un recorrido histórico de la semántica de este concepto en las Ciencias Sociales. Pues así queda en evidencia que estamos frente a un término que en distintos momentos ha servido para dar cuenta de las ambivalencias propias de todo orden político, las cuales obedecen a la tensión que se produce entre el orden considerado como ideal y el grado en que éste realmente es llevado a la práctica. En este sentido, el populismo es el reflejo de un déficit

\footnotetext{
${ }^{2}$ Algunas veces la ambivalencia entre la valoración y el rechazo al populismo puede llevar a formulaciones conceptuales sumamente confusas. Un buen ejemplo de ello es la siguiente afirmación: "En países donde el Estado ha sido debilitado o es endémicamente débil (Bolivia y Ecuador), [el populismo] es una tendencia positiva, siempre y cuando conduzca a políticas públicas en beneficio de los ciudadanos. En otros países, como Argentina y Venezuela, donde la creación del Estado está ligado al populismo redistributivo, representa la tentación de volver al pasado. [...] En términos generales, fortalecer el Estado mediante fórmulas populistas es positivo y negativo a la vez. Positivo, porque crea más políticas públicas, fomenta el empoderamiento y alivia la pobreza; negativo, porque en vez de basarse en un consenso político tiende a ser excluyente y polarizador creando Estados clientelares o de patronazgo que ofrecen favores en vez de derechos y son poco compatibles con Estados democráticos de derecho" (Gratius 2007: 22-23).
} 
de representación, así como también del intento de articular demandas insatisfechas para modificar el orden existente.

Tal como se expone en el cuadro adjunto y posteriormente se discute, es posible esquematizar tres momentos en la historia conceptual del populismo ${ }^{3}$. Este ordenamiento se produce al diferenciar fases de concepción del populismo en las Ciencias Sociales en función de tres criterios: la época que se considera, los gobiernos que se tienen como referencia y las definiciones que se dan de este fenómeno.

\section{Tres fases en la concepción del populismo en las Ciencias Sociales}

\begin{tabular}{|c|c|c|c|}
\hline & $\begin{array}{c}\text { Primera fase: } \\
\text { El populismo como } \\
\text { movimiento político }\end{array}$ & $\begin{array}{c}\text { Segunda fase: } \\
\text { El populismo como etapa de la } \\
\text { modernización } \\
\text { latinoamericana }\end{array}$ & $\begin{array}{c}\text { Tercera fase: } \\
\text { El populismo como una lógica } \\
\text { de acción política }\end{array}$ \\
\hline Época & $\begin{array}{l}\text { Entre fines del siglo } \\
\text { XIX y comienzos del } \\
\text { siglo XX }\end{array}$ & $\begin{array}{c}\text { Entre la crisis económica de } \\
1929 \text { y la irrupción del } \\
\text { neoliberalismo a comienzos de } \\
1980\end{array}$ & $\begin{array}{l}\text { Entre fines de la Guerra Fría y el } \\
\text { creciente escepticismo frente a } \\
\text { una consolidación global de la } \\
\text { democracia }\end{array}$ \\
\hline Ejemplos & $\begin{array}{c}\text { Narodniki } \\
\text { (movimientos } \\
\text { revolucionarios en la } \\
\text { Rusia zarista) y } \\
\text { People's Party } \\
\text { (Movimiento agrario } \\
\text { norteamericano) }\end{array}$ & $\begin{array}{l}\text { Gobiernos latinoamericanos } \\
\text { como el de Perón en Argentina } \\
\text { (1946-1955) o los de Vargas, } \\
\text { Kubitschek, Quadros y Goulart } \\
\text { en Brasil (1945-1964) }\end{array}$ & $\begin{array}{l}\text { Algunos regímenes híbridos o } \\
\text { ‘democracias con adjetivos' de } \\
\text { América Latina (como por } \\
\text { ejemplo Fujimori en Perú) y } \\
\text { Europa del Este (como Mečiar en } \\
\text { Eslovaquia) }\end{array}$ \\
\hline Definición & $\begin{array}{l}\text { El populismo es un } \\
\text { movimiento social } \\
\text { que se apoya en } \\
\text { ideologias agrarias y } \\
\text { propone una } \\
\text { participación del } \\
\text { pueblo sin ningún } \\
\text { tipo de instancias } \\
\text { intermedias }\end{array}$ & $\begin{array}{l}\text { El populismo es una fase de } \\
\text { transición de los países } \\
\text { latinoamericanos desde una } \\
\text { economía agraria a una } \\
\text { industrial, en donde aparecen } \\
\text { líderes carismáticos que actúan } \\
\text { en nombre del pueblo y } \\
\text { favorecen una política estatal de } \\
\text { sustitución de importaciones }\end{array}$ & $\begin{array}{c}\text { El populismo es un tipo de lógica } \\
\text { de acción política que se establece } \\
\text { en los regímenes democráticos, } \\
\text { caracterizándose por la búsqueda } \\
\text { de coaliciones heterogéneas y la } \\
\text { irrupción de un liderazgo } \\
\text { carismático que utiliza métodos de } \\
\text { conducción social que escapan los } \\
\text { mecanismos de control } \\
\text { institucional }\end{array}$ \\
\hline
\end{tabular}

\section{I.1. Primera fase: el populismo como movimiento político}

En estricto rigor, esta primera fase de la concepción del populismo se caracteriza por la apropiación de una auto-descripción, ya que ciertos movimientos políticos de fines del siglo XIX se autodefinieron como populistas y posteriormente fue recogida

\footnotetext{
${ }^{3}$ Cabe indicar que Conniff (2003:32) también describe tres fases del populismo: a) el populismo temprano o protopopulismo en las primeras décadas del siglo XX; b) el populismo clásico que va desde 1940 a 1960; y c) el resurgimiento del populismo en 1980 y la consecuente discusión en torno a la aparición de un neopopulismo hacia 1990. La esquematización que nosotros proponemos también hace una ordenación cronológica, pero el principio de categorización difiere del Coniff en dos aspectos: por un lado, interesa situar la coherencia semántica que en ciertos períodos existe al momento de definir qué es el populismo y, por otro lado, se desarrolla una perspectiva que enfatiza que el populismo es un fenómeno que no sólo incumbe a América Latina.
} 
esta definición por algunos intelectuales. Lo común de estos diversos movimientos populistas fue su reacción frente a amplios procesos de modernización, de manera que muchas veces fueron tildados como reaccionarios. Dos ejemplos resultan paradigmáticos: los Narodniki rusos y el partido norteamericano del pueblo.

Los Narodniki rusos representaban un pequeño movimiento urbano surgido a mitad de la década de 1870 que fue dirigido por intelectuales. Estos últimos se apoyaron en las ideas de Herder y Rousseau, elaborando así una idealización de la vida en las comunidades rurales. Su concepción era romántica y reaccionaria por un lado, pero por otro, contenía una particular fuerza transformadora: no sólo se distanciaba de las elites económicas y políticas establecidas, sino que también llamaba a la movilización de la población para la confrontación del capitalismo y del sistema zarista (Puhle 1986: 20). En este sentido, los Narodniki rusos tienen cierta similitud con el anarquismo y el socialismo, de modo que incluso Lenin los llegó a concebir en algún momento como un importante complemento para el orden democrático (Walicki 1969: 83-104).

Los movimientos populistas norteamericanos de fines del siglo XIX comenzaron como una revuelta frente a la industrialización que favorecía a los grandes monopolios, tratándose así de una crítica a la concentración y organización del poder tanto en el Estado Federal en particular como en el sistema capitalista en general. Estos movimientos articularon los intereses de los terratenientes y pequeños agricultores del sur y del oeste de los Estados Unidos, exigiendo la recuperación del supuesto antiguo ideal americano de la 'democracia agraria', tal y como había sido concebido por Jefferson. El punto cúlmine de estos movimientos populistas fue la formación del People's Party en el año 1891, el cual estableció como bandera de lucha la elección directa de los senadores, el voto femenino, un sistema tributario progresivo así como también la posibilidad de realizar referendos e iniciativas popular de ley. Dicho partido representaba el estallido de las pequeñas comunidades agrarias que no necesariamente tenían una solidaridad de clase (Worsley 1969:277), pero que sí mantenían una demanda de autogobierno frente a un poder central con crecientes atribuciones y estructurado cada vez más burocráticamente (Hofstadter 1969: 15-21).

A modo de resumen, el concepto de populismo puede ser definido en esta primera fase del siguiente modo: se trata de determinados movimientos sociales que se basaron en ideologías agrarias y que apelaron una participación directa del pueblo. Desde un ángulo teórico, resulta particularmente interesante el uso de la noción de 'pueblo', ya que mediante el recurso a esta categoría semántica se proyecta una imagen romántica de sociedad, con una valoración intrínseca al pasado que se caracteriza por la afirmación de la autodeterminación de las comunidades y por la demanda de una relación directa entre gobernados y gobernantes. 
En este momento histórico el populismo refleja, en cierta medida, la tensión que se produce cuando los mecanismos y organismos centrales de representación no cumplen las aspiraciones existentes frente al proceso de democratización. En este sentido, en esta etapa el populismo da cuenta de la no adecuación entre el poder de mando de los gobernantes y las aspiraciones colectivas de autodeterminación por parte de los gobernados. Planteado así, el populismo como movimiento tematiza una demanda de parte de ciertos grupos por mayor reconocimiento y autonomía, en una sociedad organizada crecientemente en base de instituciones altamente despersonalizas y burocratizadas.

De esta forma, el populismo refleja una ambivalencia del orden político de aquel entonces, ya que florece como una demanda legítima por representación y reconocimiento, pero a la vez puede ser considerado como el intento - por cierto fallido - de ciertos grupos organizados por desatender los mecanismos institucionales de representación y priorizar sus propios intereses frente al resto total de la población.

\section{I.2. Segunda fase: el populismo como etapa de la moderniza- ción latinoamericana}

Como el mismo nombre lo indica, la gran crisis económica de 1929 fue una situación que no sólo afectó al centro sino que también a la periferia. Sus consecuencias fueron especialmente dramáticas en América Latina, puesto que esta región tuvo grandes problemas para poder seguir exportando sus productos y, por lo tanto, emergió una imperiosa necesidad por establecer un nuevo modelo de desarrollo. Es así como se fue dando un terreno sociopolítico que permitió la formación de nuevos regímenes que usualmente fueron catalogados como populistas por las Ciencias Sociales. Bajo la égida de las teorías de modernización y del estructural-funcionalismo, gobiernos como el de Juan Domingo Perón en Argentina y de Getúlio Vargas en Brasil fueron tomados como ejemplos clásicos para la teorización del populismo como un específico estadio de desarrollo latinoamericano.

Característico de este estadio sería la creciente participación de los sectores medios urbanos así como de las burguesías industriales y comerciales tanto en el mercado interno como en el sistema político, la formación de un 'Estado de compromiso' entre diversas clases sociales, la implementación de una política estatal de substitución de importaciones, la movilización del pueblo en nombre de la nación así como también la irrupción de liderazgos de corte carismático y personalista (Baino 1997: 131-143, Cardoso y Faletto 1969: 102-129). Por cierto que este estadio de desarrollo se cristaliza de diferentes maneras a lo largo del continente latinoamericano. 
En el caso de Argentina, la crisis de 1929 fomentó una industrialización y una fuerte expansión del mercado interno conducida por los sectores empresariales privados. Esta transformación provocó una rápida incorporación de nuevos contingentes a la fuerza de trabajo, aunque no necesariamente se produjo su incorporación política. El gobierno de Perón intenta dar continuidad a la expansión económica, respetando el empuje del sector empresarial, pero imponiéndole cauces generales que aceleran la incorporación de las masas ya no sólo económica sino también social y políticamente (Cardoso y Faletto 1969: 111, Baino 1997: 131-139, Laclau 1978: 206-224).

En el caso de Brasil, la industrialización se llevó a cabo por acción directa del Estado, expresando éste la voluntad de una burguesía no vinculada al sector agrícola, los sectores medios y los populares a través de los sindicatos. En este caso, el Estado surge no sólo como un aparato de regulación del mercado, sino que también como un agente activo en la constitución del sistema, creando empresas públicas y fomentando la autarquía económica. Getúlio Vargas en sus tres gobiernos representa el líder que organiza tanto las alianzas inter-clases como también permite la constitución de distintos grupos sociales. Su experimento político conforma una hegemonía anti-oligárquica y logra una serie de ventajas simbólicas y materiales para las masas incorporadas en el nuevo mercado interno, aunque mantiene un esquema de participación relativamente limitado y utiliza el poder militar como estrategia de contención de demandas (Baino 1997: 140-143, Cardoso y Faletto 1969: 116-122).

Más allá de las diferencias entre los países, para comprender la particularidad de este contexto histórico resulta reveladora la obra del sociólogo italo-argentino Gino Germani, quien define al populismo como un singular fenómeno latinoamericano del período entre la primera y la segunda guerra mundial. Para Germani el populismo latinoamericano representa una fase de transición de la sociedad tradicional a la moderna, la cual encuentra su motor de transformación en la configuración de lo que él llama un 'movimiento nacional popular'. Este movimiento multiclasista generó tal grado de movilización de las masas, que la capacidad de integración del Estado se vio sobrepasada y así emergió una lucha constante por la redistribución (Germani 1965: 18-29) ${ }^{4}$. Las sociedades latinoamericanas habrían experimentado entonces una 'revolución de las aspiraciones's, en cuanto diversos grupos comenzaron a actuar en

${ }^{4}$ En Germani es fundamental la distinción entre movilización e integración, entendida la primera como el proceso psico-sociológico en que ciertos grupos tradicionales aumentan sus demandas de reconocimiento y de defensa de derechos sin una efectiva canalización por parte del sistema político a esas aspiraciones, mientras que la segunda se define como la participación legítima de las masas que se efectúa a través de los medios institucionales dentro del marco del régimen político existente (1965:21).

${ }^{5}$ Cercano a la interpretación de Germani, Torcuato di Tella (1965: 398) definió el populismo como un movimiento político con fuerte apoyo popular, con la participación de distintos sectores sociales y sustentador de una ideología anti-status quo. Di Tella le daba suma importancia a la 'revolución de las aspiraciones', que había acontecido con la ampliación de la democratización social y cómo ciertos grupos de clases medias forjaron un sentimiento en contra del status quo frente a la oligarquía dominante. A esto, le agregaba el componente emocional o ideológico que favorecía la comunicación entre los líderes y los diversos grupos que componían la masa heterogénea. La diferencia entre Germani y Di Tella es que el primero piensa que el populismo es un fenómeno propio de una transición sui generis que no ha sido capaz de seguir el modelo europeo, mientras que el segundo considera que el populismo fue el único vehículo 
nombre del pueblo y se movilizaron por la solución de la cuestión social (Germani 1962: 147-162, 1965: 12-36; Laclau 1978: 170-184).

Pese a la diversidad de autores y de definiciones que se dieron en aquella fase, es posible encontrar un hilo conductor: bajo la primacía de la teoría de la modernización y del estructural-funcionalismo fue concebido el populismo como una fase de transición de una economía agraria a una industrial, la cual se distingue por la irrupción de líderes carismáticos que ocupan el Estado para promover la industrialización economía y establecer un orden político que busca satisfacer las necesidades del pueblo. Particularmente llamativo resulta el hecho de que se trata de un fenómeno específicamente latinoamericano, en cuanto en esta región no emergió ni el fascismo ni el socialismo y el desarrollo económico no fue lo suficientemente exitoso para dar vida a un Estado de Bienestar como en Europa Continental.

Siguiendo la clásica terminología del sociólogo inglés Marschall (1977), la irrupción del populismo no implicó necesariamente la consecución de los derechos civiles y políticos, pero sí simbolizó el reconocimiento de la validez del reclamo por derechos sociales: la pobreza pasó a ser definida como un problema que no puede ser pasado por alto y que debe ser superado (Murilo de Carvalho 2005: 126). Es así como resulta comprensible que el populismo se caracterizó sobre todo por la activación de estrategias organizacionales, retóricas y en cierta medida redistributivas a favor del pueblo, que como señaló Germani, no sólo fueron promesas económicas demagógicas, sino que también experiencias simbólicas de participación aunque la mayor parte de las veces bajo el amparo de regimenes semi-autoritarios (1965:33-35).

\section{I.3. Tercera fase: el populismo como una lógica de acción polí- tica}

La última fase de tematización del populismo dentro de las Ciencias Sociales está directamente relacionada con la irrupción de la llamada 'tercera ola de la democratización'. A diferencia de la teoría de la modernización y del estructural-funcionalismo, comienza ahora a observarse al populismo como un tipo específico de lógica política, que independiente de las condiciones socio-estructurales, se establece en distintos regímenes a causa de diversos déficits institucionales en los sistemas de representación democráticos. Sobre todo en países en donde la sociedad civil y los partidos políticos resultan ser débiles, se ha dado un terreno fértil para el surgimiento de líderes capaces de hablar en nombre del 'pueblo' y de criticar a las elites establecidas, proyectando así un difuso ideal al cual pretenden conducir a la sociedad.

Para esta tercera fase es decisiva la irrupción de nuevos gobiernos después de un pasado autoritario, los cuales si bien fueron elegidos democráticamente, actúan a su disponible de reforma en América Latina (Baino 1997: 124) 
vez en contra de determinados pilares de la democracia liberal. En este sentido, la tercera ola de la democratización pavimentó el camino para la irrupción de nuevos regimenes que estaban lejos del proclamado 'fin de la historia' por Fukuyama, es decir, del optimismo en torno a la consolidación universal de la democracia liberal. Dos ejemplos paradigmáticos de este desenvolvimiento representan los casos de Alberto Fujimori en Perú y de Vladimir Meciar en Eslovaquia.

A mediados del año 1990, Perú vivía una grave situación económica y fuertes conflictos armados internos por las guerrillas. Luego de una década pérdida en términos económicos, el gobierno de Fujimori representó para el electorado el camino más inmediato para la superación de la crisis en que se encontraba el país. Una vez en el poder, aplicó una reforma neoliberal a la estructura económica del país que se vio frenada en un primer momento por los otros poderes del Estado. Es así como decidió suspenderlos y realizar un auto-golpe en 1992 en conjunto con las Fuerzas Armadas, instalando luego un régimen de carácter fuertemente presidencialista. Luego de una reforma constitucional, impuso diversos programas redistributivos para los sectores más excluidos de la población (Weyland 2003: 6-11) y logró su reelección en 1995. Sin embargo, el año 2000 terminó renunciando por graves acusaciones de corrupción contra su asesor principal Vladimiro Montecinos y diversas denuncias sobre atropello a los Derechos Humanos (Castro 2002).

En el caso de Eslovaquia, a principios de la década de 1990 el Estado federal formado en conjunto con Checoslovaquia sufría una crisis producto del malestar de los eslovacos frente a la integración con el régimen comunista checo. La insatisfacción procedía de dos fuentes. Por un lado, por las diferencias entre checos y eslovacos ante el status de ciudadanía de ambos grupos, de modo que los eslovacos sentían una discriminación de parte de los checos en el plano del reconocimiento simbólico. La segunda fuente, fue la escasa respuesta de la elite dirigente ante tal malestar (Skolkay 2000: 4-9).Vladimir Meciar fue uno de los políticos más activos en patrocinar la independencia de Eslovaquia frente al régimen comunista checoslovaco, fomentando un ideario nacionalista y una radicalización democrática del Estado federal, fundando el Movimiento por una Eslovaquia Democrática (HZDS). Como primer ministro hizo efectiva la independencia y rápidamente organizó una reforma de la economía, vendiendo las empresas deficitarias del Estado a inversores privados tanto nacionales como extranjeros. Logró importantes alianzas con los sectores obreros y trabajadores del país, fomentando políticas redistributivas para estos grupos. Después de una breve destitución lograda por parte de sus adversarios, consiguió el voto popular para ser reelecto, aplicando luego diversas medidas de rasgo autoritario.

Interesante de ambos ejemplos es que los mencionados regímenes se encuandran en la definición de diversos tipos de 'democracias con adjetivos' (Collier y Levistky 1997), particularmente la propuesta de O’Donnell (1994) en torno a la llamada 
'democracia delegativa'. Pero estos regimenes presentan además otra característica relevante: ellos propiciaron la privatización de empresas públicas, la flexibilización del mercado laboral y la disminución de los aranceles a las importaciones, con lo cual perdió validez la frecuente demonización de los economistas frente al populismo en cuanto sistema de dilapidación de las finanzas públicas (Knight 1998: 241-243).

El análisis de estos nuevos regímenes a través del concepto de populismo implicó un giro radical de lo que usualmente se entiende por éste. A partir de entonces ya no queda duda que el populismo se puede dar tanto en gobiernos de izquierda como de derecha y que puede echar raíces tanto en América Latina como en Europa. Por otra parte, pasan a ser insuficientes las explicaciones desarrollistas leídas en clave de factores socio-estructurales. En efecto, diversos autores han llamado a abandonar los presupuestos anteriores y a estudiar el populismo exclusivamente en su dimensión política. Canovan propone hacer un viraje a los contenidos políticos e ideológicos del populismo, en vez de las condiciones estructurales (1999: 3), Laclau piensa que el populismo es la vía para comprender algo relativo a la constitución ontológica de lo político como tal (2005a: 91), Roberts declara que el populismo es ahora entendido esencialmente en su carácter político (2003: 4), Savarino llama a centrarse en la morfología política de éste (2006: 80), Taguieff señala que el populismo ahora sólo puede ser designado como una dimensión de la acción o el discurso político (1996: 42) y Weyland señala que éste tiene como centro la dimensión política y tan sólo accidentalmente una característica socio-económica (2001: 4).

Principalmente en los años noventa y a principios de siglo XXI, el populismo empieza a ser considerado como una lógica de acción política aplicable a diversos modelos ideológicos y que se caracterizaría por tres rasgos fundamentales. Primero: un estilo político basado en un estrecho vínculo entre los líderes políticos y sus seguidores (Knight 1998: 226; Canovan 1999: 5). Segundo: una temporalidad donde se proclama la utopía de las soluciones instantáneas a los problemas de larga data (Hermet 2003: 12).Y tercero: el desarrollo de una estrategia de obtención y ejercicio del poder a través de la cual un líder carismático gobierna sin contra-balance de las instituciones propias del Estado de Derecho. (Weyland 2001: 13) . $^{6}$

En síntesis, lo que los clásicos teóricos latinoamericanos vieron como algo externo al populismo, en esta tercera fase se pone como punto medular de la interpretación: se abandona la centralidad de los factores socio-económicos, para concentrarse en la lógica de acción política del populismo. De tal manera, dentro de esta fase se puede definir al populismo como aquella lógica que tiende a formar coaliciones heterogéneas mediante un liderazgo carismático y paternalista, el cual no sólo recurre a métodos redistribituvos o clientelares para mantener el vínculo con el electorado, ${ }^{6}$ La mayoría de estas definiciones compite tanto por lograr una mayor precisión conceptual a través de enmarcamientos de una lógica política, como por lograr abarcar la descripción del mayor número de regímenes. Weyland (2001) probablemente es el que más ha insistido en la necesidad de establecer una mayor especificidad y a la vez una mayor diferenciación conceptual con otras lógicas de acción política como pueden ser el clientelismo o el patrimonialismo. 
sino que también actúa dentro de los marcos generales de la democracia liberal y al mismo tiempo tiende a presentar rasgos autoritarios que se desacoplan de los sistemas de control institucionales.

Si bien en esta tercera fase hay una permanente reflexión por categorizar al populismo como un determinado régimen político, es dentro de este propio esfuerzo en que aumenta la ambivalencia respecto a la relación con la democracia. Esto por dos motivos.

En primer lugar, porque al definir al populismo como lógica de acción se pierden los contornos entre éste y la democracia, o más grave aún, entre éste y la política. El mismo Laclau en su última obra postula que "no existe intervención política que no sea hasta cierto punto populista" (2005a: 192). Weyland por su parte llega a decir que el neopopulismo, debido a que su modo de apelación al pueblo se constituye crecientemente a través del uso de los medios de comunicación y de las encuestas de opinión pública, es compatible con la democracia liberal (2001:16).

En segundo lugar, la ironía del llamado a las representaciones directas propias del populismo es que el líder del movimiento en cuestión adquiere un grado tal de poder personal que es dificil de conciliar con las aspiraciones democráticas (Canovan 1999: 14). No en vano señala Arditi (2005) que el populismo puede ser visto como un reverso de nuestras democracias, en donde la ciudadanía termina convirtiéndose en una cáscara vacía y las políticas redistributivas en un instrumento de dominación. Reaparece así el miedo frente al populismo; aquel miedo que pone un freno a la hora de afirmar con tanta prontitud la compatibilidad entre democracia y populismo.

En este sentido, la ambivalencia conceptual del populismo en esta tercera fase es más radical que en las fases anteriores, ya que la posibilidad de confundir la lógica de acción del populismo con toda política o con la democracia misma contiene el riesgo de no advertir cuál es en definitiva la singularidad del populismo. De este modo, la tercera fase en la que actualmente nos encontramos demanda una nueva aproximación teórica, la cual sea capaz de dar cuenta de la ambivalencia inherente al populismo y que a su vez explique por qué éste parece contar con tan buena salud. Esta es la tarea de la próxima sección.

\section{Hacia una teoría política del populismo}

La presentación anterior de tres fases históricas del concepto de populismo en las Ciencias Sociales debe ser vista como un preludio teórico que enfatiza la dificultad para arribar a una definición consensuada sobre este fenómeno. Sin duda alguna, cada una de las fases propuestas podría estudiarse de forma más acabada, así como 
también podrían plantearse diferenciaciones más específicas o analizarse ciertos casos más detalladamente. No obstante, el interés radica en la exposición de una suerte de mapa general con las distintas concepciones del populismo que muestre no sólo la ambivalencia del concepto, sino también que su teorización sufre desde comienzos del siglo XXI una transformación.

Tres síntomas son signo de ello. Primero: la gradual emergencia de ciertas obras que reivindican una desnormativización del concepto, es decir, que buscan trascender el uso de definiciones que persiguen la demonización o glorificación del fenómeno populista (Decker 2006; Meny y Surel 2003; Panizza 2005). Segundo: en Europa Occidental han venido apareciendo partidos políticos de derecha de corte populista, de manera que el populismo ya no es visto sólo como un fenómeno de la periferia sino que también del centro.Y tercero: por primera vez se comienza a discutir en la teoría política si acaso no existe una compatibilidad entre la democracia y el populismo.

Particularmente indicativo de esta nueva atmósfera intelectual resulta el ya mencionado artículo de Benjamín Arditi (2005), en donde se plantea la siguiente metáfora: el populismo se asemeja a la situación cuando un amigo llega tarde y ebrio a una comida. Él no respeta los buenos modales en la mesa, habla fuerte e incluso coquetea con las mujeres de los invitados. Por cierto que el dueño de casa se molesta por el comportamiento de su invitado, pero no lo puede echar y, por lo tanto, intenta controlar la situación para que todos se sientan cómodos. El punto central es que el invitado ebrio pertenece al grupo y su actuar se caracteriza - entre otras cosas - por la revelación de una serie de verdades incómodas.

De traducirse esta metáfora a la esfera política, podría decirse que el populismo actúa de modo similar al invitado ebrio antes expuesto: él tiende a ingresar a un escenario político legitimado por las reglas del Estado de Derecho y la democracia liberal (es un invitado, no un extraño), aunque quebranta una serie de disposiciones del orden instituido, de manera que es criticado por diversos actores e instituciones. Sin embargo, gracias a él emergen ciertas demandas de carácter reivindicativo que la política no es capaz de resolver. En otras palabras, el populismo despierta fuerzas que simbolizan una irritación frente a una serie de disfunciones del orden democrático existente. Una vez que estas fuerzas se activan, resultan muy dificiles de domesticar y se transforman en verdades incómodas que hasta antes usualmente eran pasadas por alto.

En consideración de esta nueva atmósfera intelectual resulta posible presentar el bosquejo de una teoría política del populismo. Para ello es útil plantear el concepto típico ideal subyacente en el siguiente trabajo: el populismo es un experimento político cuyo surgimiento está relacionado con el fracaso de las elites y que se distingue por la activación de emociones para constituir una entidad colectiva llamada pueblo, intentándose así dar vida a un singular modelo de dominación social que debe ser clasificado más allá de la democracia liberal y del totalitarismo. 
La definición típico ideal propuesta contiene cuatro ejes analíticos que están marcados en letras cursivas y que demarcan los lineamentos de una teoría política del populismo, los cuales se detallan brevemente a continuación.

\section{II.1. El populismo como experimento político}

El populismo debe ser concebido como un experimento político de dominación que es comandado por un actor - ya sea un movimiento social, un partido político o un líder carismático -, el cual intenta llegar al poder mediante mecanismos legales o ilegales para construir un nuevo modelo de sociedad. La definición del populismo como experimento antes que como régimen político busca subrayar que se trata de un constante proceso, el cual en ninguna de sus fases de implementación puede ser considerado como finalizado.

Así se puede comprender porque los populismos no pueden ser definidos a priori de derecha o de izquierda, puesto que no tienen un cuerpo ideológico claro, sino que en cada caso histórico se forman de un modo singular y desarrollan líneas de intervención sui generis. De tal manera, hoy día se puede observar un 'populismo de izquierda' en ciertos países de América Latina (como por ejemplo Chávez en Venezuela), mientras que algunos países de Europa Occidental emerge un 'populismo de derecha' (como por ejemplo Haider en Austria).

Para comprender al populismo como experimento político resulta particularmente valiosa la última obra de Ernesto Laclau (2005a). En base a la teoría del discurso, define él al populismo como un modo de articulación lingüística que permite la irrupción de un singular tipo de identidad colectiva. Dicha argumentación descansa en la distinción entre la 'lógica de la diferencia' y la 'lógica de la equivalencia', tratándose de dos conceptos que el mismo Laclau (2005b) explica a través de la siguiente situación fictiva.

Un grupo de personas de un barrio está interesado en la implementación de un nuevo recorrido de bus para así poder llegar más rápido a sus puestos de trabajo. Debido a ello se organizan y conversan con el alcalde, quien los escucha y acepta su petición. En este caso se trata de una 'lógica de la diferencia', ya que la demanda se inscribe como un momento particular de cada individuo y, por tanto, no surje una identidad colectiva entre los miembros del grupo. De tal manera, el orden político no es cuestionado en momento alguno, puesto que no compiten distintas demandas entre sí y tampoco es vista la demanda establecida como un problema de fondo de la situación general de todos los involucrados.

Pero imaginemos la situación inicial de nuevo y que ahora se acumulan una serie de demandas insatisfechas. Supongamos así que el grupo de personas de este barrio está 
descontento no sólo por la inexistencia de un recorrido de bus, sino que también por fallas en la distribución del agua potable, la calidad de la educación pública y por la falta de seguridad. De suceder esto, existe el potencial para la aparición de una 'lógica de la equivalencia': las distintas demandas son agregadas y emerge así el momento político del populismo, es decir, gracias al no cumplimiento de una serie de demandas se logran unir diversos grupos sociales bajo una misma bandera de lucha.

¿Cuál es el aspecto de este nuevo proyecto político y qué metas persigue? La respuesta es simple: no existe un modelo sociedad claro y tampoco hay metas evidentes. La definición del populismo como articulación discursiva (en el decir de Laclau) o como un experimento político (en el sentido que nosotros le damos) intenta subrayar que se trata de un significante vacío. La similitud de los diversos populismos radica entonces en la capacidad que éstos tienen para unificar diferentes demandas, de modo que grupos altamente heterogéneos e incluso rivales se integran mediante la definición de un enemigo en común, aunque no necesariamente tengan un proyecto de identidad definido entre ellos.

En función de este argumento resulta fácil comprender, porque la simplicidad simbólica del populismo es a su vez la condición de su eficacia: dado que su tarea primordial consiste en la reunión de grupos altamente heterogéneos bajo un mismo techo, sólo puede el populismo lograr esto mediante la simplificación y reducción de los elementos particulares hasta un mínimo posible de componentes unitarios. Este proceso alcanza su punto cúlmine cuando la homogeneización se logra a través de la simple enunciación de una palabra: el nombre del líder del experimento político.

Mediante la teorización del populismo como un experimento político que opera como un significante vacío resulta posible elaborar una fórmula respecto a la posibilidad de su emergencia: mientras más demandas sociales son trabajadas de forma efectiva por un sistema institucional diferenciado, menor es la chance de que emerja una 'lógica de la equivalencia' y, por lo tanto, de que se instale el populismo.

\section{II.2. El populismo como resultado del fracaso de las elites}

La irrupción de experimentos populistas está directamente ligada con la incapacidad de las elites para escuchar y cumplir las demandas de la sociedad. Es por ello que el populismo se caracteriza por una radicalización de la clásica distinción de Carl Schmitt (1932) entre amigo y enemigo, ya que así son denunciados quienes están el poder como corruptos e incapaces, posibilitándose la generación de una identidad común entre los denunciantes. De tal manera, los experimentos populistas tienden a la negación de existentes clivajes horizontales (como por ejemplo derecha e izquierda) y en su lugar proponen clivajes verticales (como por ejemplo ricos y pobres). En 
consecuencia, no resulta una casualidad que aparezcan neologismos como Berlusconismo, Chavismo o Peronismo. Ellos indican la personalización de los experimentos populistas, en cuanto sólo se puede estar a favor o en contra de ellos. Un camino intermedio no existe, ya que dichos líderes encarnan el rechazo frente a las elites establecidas y el deseo de fundación de un nuevo orden.

Si el fracaso de las elites es un terreno fructífero para la irrupción de experimentos gubernamentales populistas, resulta posible levantar la siguiente tesis: mientras mayor es la desilusión de la población respecto a las elites existentes, más categórica será la reacción y el cambio de preferencia del electorado. Una serie de estudios fundamentan y legitiman esta tesis (Decker 2006, Taggart 2003, Werz 2003), ya que la formación de un cartel de elites permanente entre los grandes partidos políticos funge como catalizador para la irrupción del populismo. De hecho, este tipo de desarrollo se puede observar en casos muy disímiles, como por ejemplo en el peronismo clásico en Argentina, así como también en el surgimiento de Chávez en Venezuela o en su momento de Haider en Austria.

Desde este punto de vista, elites y masas mantienen una relación orgánica entre sí que depende tanto del cumplimiento de ciertos objetivos como de la efectiva generación de autoridad. De no cumplirse estos objetivos o si las elites pierden su prominencia, aumenta la posibilidad de que irrumpa un experimento político populista. Teniendo esto en consideración, resulta posible diagnosticar dos catalizadores que explican el actual (re)surgimiento del populismo a lo largo del mundo: la creciente de la desigualdad social y el aumento de la complejidad.

Concerniente a la desigualdad social, a estas alturas es su crecimiento una tesis empíricamente demostrada tanto para el centro como para la periferia.Visto así, la conformación de elites de corte meritocrático será uno de los grandes desafios para la democracia liberal del siglo XXI. De no cumplirse esto, aumentarán las chances de que se constituyan contra-elites que ganarán autoridad y poder gracias al denunciamiento de la creciente clausura de las elites establecidas. Desde este ángulo, las consignas de Le Pen en Francia contra los inmigrantes y los ataques de Morales en Bolivia contra los blancos pueden ser vistos como fenómenos similares: se trata de discursos populistas a través de los cuales parte de la población demuestra su malestar debido a las desigualdades sociales o su temor frente a su posible crecimiento.

El segundo catalizador se basa en una tesis habitual sobre el desarrollo de las sociedades contemporáneas. El diagnóstico de una creciente complejidad social es ampliamente aceptado e indica que la conducción de la sociedad es cada vez más difícil, puesto que la autonomización de distintos campos de acción dificulta la posibilidad de una coordinación funcional central guiada por la política. Una posible solución sería la potenciación de los marcos ideológicos e institucionales que permiten una intensificación de la integración horizontal de las elites, es decir, un aumento de la 
comunicación entre elites que provienen de distintas esferas de poder y que no necesariamente mantienen un contacto fluido entre si.

Sin embargo, esta posible solución tiene una contrapartida: una excesiva integración horizontal entre las elites conlleva su cerrazón y deslegitimación, de manera que se pavimenta el camino para el triunfo de un discurso político anti-elitista. No hay mejor ejemplo de esto que la constante discusión en torno a la crisis de legitimidad de la Unión Europea. Debido a su creciente institucionalización, se ha ido formando una tecnocracia transnacional que poca o nula relación mantiene con la ciudadanía y que dificilmente puede legitimarse mediante un espacio de opinión pública (Bach 1999). De este modo, aumenta el potencial para la formación de discursos populistas que denuncian el carácter elitista del proyecto de unificación europeo.

A pesar de lo anterior, no hay que caer en una divinización del resentimiento antielitista del populismo. El exitoso surgimiento de experimentos gubernamentales populistas depende de la constitución de nuevas elites capaces de fundar una contrahegemonía y de dar sustento a un nuevo líder. En este sentido, sería un error analizar al populismo bajo una teoría de los 'grandes hombres'. Como bien lo demuestran las experiencias latinoamericanas de mitad del siglo XX, el establecimiento del populismo depende de la formación un cartel de elite encargado de generar estabilidad para la formación de un nuevo modelo de orden deseado. De hecho, una de las diferencias importantes entre el populismo de Perón en Argentina y el de Vargas en Brasil, es que este último tuvo la capacidad de armar un cartel de elites leal al régimen, mientras que en el caso del peronismo no logró consolidarse un cartel de elites, sino que se produjo más bien una constante circulación y con el tiempo aumentaron los conflictos al interior de los cuadros dirigentes (Fausto y Devoto 2004: 330-331).

\section{II.3. El populismo como reflejo de política pasional}

La teoría política contemporánea presenta cierta ceguera frente a las emociones y las pasiones como un elemento constitutivo de todo orden social. En gran medida esto se debe a la preponderancia del pensamiento en torno a la democracia liberal y la consiguiente tendencia a imaginar un modelo de sociedad en donde los conflictos son discutidos y racionalizados, sin existir la necesidad de tener que recurrir a emociones colectivas para reivindicar demandas sociales y movilizar a la sociedad para que éstas sean solucionadas (Mouffe 2007). Si se acepta en cambio que tanto las emociones como las pasiones son connaturales a todo orden social, entonces es posible trascender la usual crítica que se le hace al populismo por su supuesto carácter 'irracional'.

En efecto, una condición absoluta para la emergencia de un experimento populista es la construcción de una identidad política basada en emociones y no sólo en argu- 
mentos racionales como hipotéticamente sucede en un orden liberal. Este supuesto está relacionado con nuevas investigaciones en el campo de los movimientos sociales, las cuales demuestran que la movilización de la sociedad depende tanto de intereses racionales como de factores emocionales (Eder 2000, Goodwin et al. 2001). La ventaja de esta perspectiva es que nos permite entender al populismo ya no como una fuerza 'irracional', sino que más bien como una fórmula de articulación política que se origina por el malestar de la población frente a los defectos de un orden democrático existente.

Si las emociones están envueltas en el proceso mediante el cual los individuos adhieren a movimientos sociales, entonces es posible concebir a las emociones como catalizadores para la participación. Ello se explica por la 'lógica de la equivalencia', ya que a través de ella se genera placer colectivo y reconocimiento social. De pronto está vinculado el problema de un individuo con el de su vecino, de modo que ambos se unen junto a otras personas que comparten el mismo malestar y construyen un enemigo común. Es así como la movilización equivale a una defensa de su dignidad social, de modo que resulta lógico pensar que mientras el populismo es más rico en elementos culturales (como por ejemplo ídolos, rituales, etc.), mayor es su activación de emociones que permiten la generación de una solidaridad en común.

El hecho de que la formación del populismo descanse más en la pasión que en la razón indica una de sus grandes debilidades políticas: el problema de su duración. Criterios racionales son mucho más fáciles de estabilizar que factores emocionales. De este modo, la permanencia del populismo depende de su constante capacidad para activar pasiones colectivas. Para ello recurre a la explotación de nichos de atención emocional, tales como discursos e imágenes que despiertan emociones como indignación, miedo y odio para así mantener viva la distinción entre amigo y enemigo en la sociedad.

Sin embargo, las emociones están destinadas a ir perdiendo su fuerza a lo largo del tiempo. Como bien indica Hirschmann (1988) en su clásico estudio, las personas se mueven de la esfera pública a la privada producto del gradual agotamiento de aquellas pasiones que fungen como motor para la acción colectiva. En pocas palabras: las emociones no sólo son bienes escasos, sino que son también inestables y de corta duración. Los populistas saben muy bien esto y debido a ello se esmeran en la constante activación de pasiones colectivas.

Un sustento empírico de la importancia que las emociones tienen para el populismo es su íntima relación con los medios de comunicación de masas y, sobre todo, con un tipo particular de discurso mediático. Así, por ejemplo, es imposible comprender los populismos latinoamericanos de mediados del siglo XX si se pasa por alto la expansión que entonces experimentó la radiofonía y su uso político por parte de diversos actores (Martín-Barbero 1998: 170-193). Líderes como Perón en Argentina o como 
Vargas en Brasil no sólo eran brillantes oradores, sino que tenían también un nuevo medio de comunicación a su disposición. De hecho, gran parte de la popularidad de Evita Perón provenía de su labor en el radioteatro.

En consecuencia, el populismo trabaja mano a mano con los medios de comunicación de masas para producir a través de ellos un tipo de discurso que busca una constante activación de las emociones. Para ello recurre a variadas estrategias de escenificación, como la teatralización y la creación de falsos acontecimientos. En todo caso, este tipo de estrategias adquieren en el día de hoy una creciente relevancia, ya que ellas representan tácticas de marketing en una opinión pública global que funciona menos según los criterios del modelo de Habermas y más según la lógica de un gran mercado de generación de atención (Frank 1998). De tener cierta plausibilidad este diagnóstico, resulta lógico suponer que la democracia del siglo XXI tendrá una tendencia estructural hacia el populismo. Pues ella requiere de los medios de comunicación de masas para activar pasiones capaces de movilizar a una sociedad cada vez más sobresatisfecha e inundada por demandas mercantiles (Meyer 2001).

\section{II.4. El populismo: ni democracia liberal ni totalitarismo}

Como ya se indicó con anterioridad, una gran mayoría de las definiciones del populismo tienden a demonizar o divinizar este fenómeno político. Para sortear este problema conviene distinguir al populismo de la democracia liberal y del totalitarismo. De este modo se plantean dos polos que no sólo delimitan las fronteras del populismo, sino que también acentúan su carácter nebuloso para la teoría política.

Como bien es sabido, la democracia liberal representa un tipo de gobierno representativo que se basa en un Estado de Derecho que descansa en el respeto de una constitución que garantiza los Derechos Humanos. Característico de una democracia liberal es su intención de limitar la omnipotencia del Estado y para ello recurre a una serie de check and balances, los cuales se encargan de procesar distintas demandas ciudadanas e impiden la concentración del poder político en la figura del jefe de Estado. Dicho de forma provocativa y recurriendo a una metáfora propia del lenguaje de la guerra, es posible decir que la democracia liberal actúa siguiendo el principio divide et impera (divide y domina): ella se esmera en la reproducción de las diferencias entre las distintas demandas ciudadanas, de modo que resulta prácticamente imposible la emergencia de conflictos que abarcan a la totalidad social.

A diferencia de la democracia liberal, el populismo articula diferentes demandas ciudadanas, posibilitando así la emergencia de conflictos que abarcan a la totalidad social, los cuales a su vez levantan una línea de demarcación frente a un enemigo. De tal manera, no sólo se cuestiona la validez de un consenso racional en el sentido 
de Habermas, sino que asimismo se intensifica la dimensión pasional de lo político. Es así como vuelven a aparecer aquellas pasiones que para muchos intelectuales son vistas como un mero anacronismo y, por lo tanto, la pluralidad de valores ya no puede ser concebida como una realidad armónica y pacífica. Muy por el contrario: aumenta el antagonismo social y un líder se transforma en la encarnación del pueblo.

Por cierto que esta última frase se asocia fácilmente con el totalitarismo, aun cuando este último no puede ser concebido como sinónimo del populismo. Determinante para esta diferenciación es el respeto del populismo de las reglas básicas de la democracia o, mejor dicho, su cercanía al modelo de poliarquía definido por Dahl (1972). De hecho, los experimentos populistas demuestran un relativamente alto nivel de tolerancia a la libertad de expresión y a la competencia política. Dicho de forma poco diplomática, personajes como Berlusconi o Chávez revelan ciertas tendencias totalitarias, pero a su vez se someten a las decisiones del pueblo, como lo demuestra la reñida elección de Romano Prodi como Presidente de Italia en el año 2006 o la negación de la reforma a la constitución de Venezuela a fines del año pasado.

Al contrario de lo que sucede con el populismo, el totalitarismo tiene la pretensión de conducir absolutamente a la sociedad, de modo que elementos básicos de un orden democrático - tales como la realización de elecciones libres y limpias o la tolerancia de partidos de oposición - son pasados por alto. Es por ello que Gentile (2006) define con razón al fascismo como una religión política que intenta realizar una revolución antropológica interesada en la formación de una civilización. Desde este punto de vista, es posible plantear que el totalitarismo es una radicalización de un experimento populista, siendo reemplazada la ambivalencia democrática del populismo por claras tendencias totalitarias ${ }^{7}$. En otras palabras, el totalitarismo puede ser concebido como el hermano mayor o la oveja negra del populismo.

\section{Conclusión}

En toda sociedad, el sistema político intenta representar las distintas demandas particulares que surgen en el seno de la población y para ello fija una concepción ideal de orden capaz de agrupar la totalidad de intereses. La democracia es una de estas concepciones ideales, la cual comenzó a ganar preponderancia con posterioridad de la revolución francesa y norteamericana. No obstante, la definición de qué es la democracia y cuáles son los componentes que la caracterizan es una materia que genera amplio debate. Es este sentido que se puede observar en términos históricos una constante lucha por la democratización, es decir, por la modificación y la ampliación de

${ }^{7}$ Esto abre la posibilidad de que un experimento populista pueda transformarse en un régimen totalitario. Algunos analistas del caso venezolano han planteado que está podría ser la situación actual, cuando el gobierno de Chávez no sólo pretende el control de los medios de comunicación, sino de la educación y de la cultura (Arenas 2007). 
lo que se considera como un orden democrático.

Detrás de las luchas por la democratización suele ir de la mano el populismo, el cual viene a dar cuenta de la distancia entre el orden ideal y el orden existente.Visto así, el populismo refleja una ambivalencia que es propia a cualquier régimen político, ya que nunca se da una conjunción perfecta entre la pluralidad de los intereses existentes y el modelo de organización política que instala un Estado soberano. En otras palabras, el populismo puede ser concebido no sólo como reflejo de un déficit de representación, sino que también como el constante intento de articular demandas insatisfechas para modificar así el orden establecido. De hecho, la revisión histórica de la semántica del populismo ha dejado en claro que este concepto es usado para dar cuenta de las ambivalencias que son inmanentes a todo orden político.

En consecuencia, el populismo no es per se 'bueno' o 'malo' para la democracia, ya que él posibilita la emergencia de experimentos políticos con dos fuerzas inherentes: por un lado, una fuerza que a la larga genera legitimidad para el sistema político debido la tematización de disfunciones del orden democrático y, por otro lado, una fuerza que radicaliza las identidades colectivas y que puede llegar a la negación del pluralismo político. Es por ello que el arte del populismo radica en su capacidad de moverse entre ambas fuerzas, de modo tal que no tiene sentido caer en una demonización o divinización de este fenómeno.

Quien adhiere a la democracia liberal se preguntará con razón si acaso el populismo no puede ser concebido como una malformación política. Esto sólo puede suceder si es que determinados criterios normativos y/o procesuales de un orden ideal - como lo es la democracia liberal - son prefijados. Pero el problema es que dichos criterios inevitablemente varían a lo largo del tiempo y del espacio. Así, por ejemplo, la actual democracia norteamericana no tiene grandes problemas con la existencia de la pena de muerte, mientras que la ejemplar democracia suiza recién en el año 1971 permitió el voto a las mujeres.

De tal manera, el populismo no debe ser pensado como una malformación política. Más allá de sus malos modales, el populismo es una señal de que la democracia nunca es un estado pasivo, sino que se trata más bien de una constante adecuación a las cambiantes demandas y valores de la sociedad. Por ello es que resulta tan dificil llegar a un consenso conceptual respecto a lo que efectivamente es el populismo, puesto que él viene a simbolizar el persistente e irremediable déficit entre un supuesto orden ideal y su materialización en la vida real. El populismo tematiza entonces las ambivalencias imanentes a todo orden político y para lograr esto es preciso desnormativizarlo. 
EL POPULISMO COMO EXPERIMENTO POLÇITICO: HISTORIA Y TEORÍA POLÍTICA DE UNA AMBIVALENCIA RaImundo Frei / Cristóbal Rovira Kaltwasser

\section{Bibliografía}

Abts, K. y Rummens, S. (2007): Populism versus Democracy, en: Political Studies. Vol 55, pp. 205-424.

Arditi, B. (2005): Populism as an Internal Periphery of Democratic Politics, en: Panizza, Francisco (Ed.): Populism and the mirror of democracy.Verso, Londres.

Arenas, N. (2007): Chávez. El mito de la comunidad total, en: Perfiles Latinoamericanos. $N^{\circ} 30, p p .153-183$.

Bach, M. (1990): Die Bürokatisierung Europas. Verwaltungseliten, Experten und politische Legitimation in Europa. Campus, Frankfurt a.M. y Nueva York.

Baino, D. (1997): Características estructurales del populismo latinoamericano: las experiencias del varguismo en Brasil (1930-1945 y 1951-1954) y del peronismo en Argentina (1946-1955). En: Cuadernos del CENDES. N³5, 121-147.

Canovan, M. (1999): Trust the People! Populism and the Two Faces of Democracy, en: Political Studies, XLVII, 2-16.

Cardoso, F. H. y Faletto, E. (1969): Dependencia y desarrollo en América Latina. Siglo XXI, México D.F.

Castro, E. (2002): Cultura política y corrupción en la era del gobierno de Fujimori.Y algunos rasgos del gobierno de Toledo: 1990-2002. Hovedoppgave, Universidad de Bergen.

Collier, D. y Levitsky, S. (1997): Democracy with adjectives: conceptual innovation in comparative research, in: World Politics, Vol. 49, No. 3, pp. 430-451.

Conniff, M. (2003): Neo-Populismo en América Latina. La década de los 90 y después, en: Revista de Ciencia Política. Vol. XXIII. Nº1, pp. 31-38.

Dahl, R (1972): Poliarchy. Participation and Opposition. Yale University Press, New Heaven y Londres.

Di Tella, T. (1965): Populismo y Reforma en América Latina, en: Desarrollo Económico. Vol. 4, N¹6, pp. 391-425.

Decker, F. (2006): Die populistische Herausforderung. Theoretische und Ländervergleichende Perspektive, en: Decker, F. (Ed.): Populimus: Gefahr für die Demokratie oder nützliches Korrektiv? VS Verlag, Wiesbaden.

Eder, K. (2000): Kulturelle Identität zwischen Tradition und Utopie. Soziale Bewegungen als Ort gesellschaftlicher Lernprosseze. Campus, Frankfurt a.M. y Nueva York. 
Fausto, F. y Devoto FJ. (2004): Brasil e Argentina. Um ensaio de história comparada (18502002). Editora 34, São Paulo.

Frank, G. (1998): Ökonomie der Aufmerksamkeit. Hanser, Munich y Viena.

Gentile, E. (2006): Politics as religion. Princeton University Press, Princeton.

Germani, G. (1962): Política y sociedad en una época de masas: de la sociedad tradicional a la sociedad de masas. Paidos, Buenos Aires.

Germani, G. (1965) Democracia representativa y clases populares, en: Di Tella T., Germani G. y Ianni O. Populismo y contradicciones de clases. Editorial ERA, México D.F.

Goodwin, Jeff, Jasper, James M. y Poletta, Francesca (Ed.) (2001): Passionate Politics: Emotions and Social Movements. The University of Chicago Press, Chicago y Londres.

Gratius, S. (2007): La "tercera ola populista" de América Latina. En: FRIDE - Documento de Trabajo, No.45.

Hermet, G. (2003): El populismo como concepto, en: Revista de Ciencia Política. Vol. XXIII, $N^{\circ} 1$, pp. 5-18.

Hirschman,A. O. (1988): Engagement und Enttäuschung. Über das Schwanken der Bürger zwischen Privatwohl und Gemeinwohl. Suhrkamp, Frankfurt a.M..

Hofstadter, R. (1969): Estados Unidos. En: Gellner, Ernest y Ionescu, Ghita (Ed.). Populismo, sus significados y características nacionales. Amorrortu Editores, Buenos Aires, pp. 15-38.

Knight,A. (1998) Populism and Neo-Populism in Latin America, especially Mexico, en: Journal of Latin America Studies, Vol.30, No2, pp. 223-248.

Laclau, E. (1978): Política e ideología en la teoría marxista. Capitalismo, fascismo, populismo. Siglo XXI, Buenos Aires.

Laclau, E. (2005a): La razón populista. Fondo de Cultura Económica, Buenos Aires.

Laclau, E. (2005b): Populism: What's in a Name?, en: Panizza, Francisco (Ed.): Populism and the mirror of democracy. Verso, Londres.

Marshall, T.H. (1977): Class, citizenship and social development. Chicago University Press, Chicago.

Martín-Barbero, J. (1998): De los medios a las mediaciones. Comunicación, cultura y hegemonía. Gustavo Gili, México D.F. 
EL POPULISMO COMO EXPERIMENTO POLÇITICO: HISTORIA Y TEORÍA POLÍTICA DE UNA AMBIVALENCIA Raimundo Frei / Cristóbal Rovira Kaltwasser

Meyer,T. (2001): Mediokratie. Die Kolonisierung der Politik durch die Medien. Suhrkamp, Frankfurt a. M.

Mouffe, C. (2007): En torno a lo político. Fondo de Cultura Económica, Buenos Aires.

Murilo de Carvalho, J. (2005): Cidadania no Brasil. O longo caminho. Civilização Brasileira, Rio de Janeiro.

O'Donnell, G. (1994): Delegative democracy, in: Journal of Democracy, Vol. 5, No. 1, pp. 55-69.

Puhle, H.J. (1986): Was ist Populismus?, en: Dubiel, H. (Ed.): Populismus und Aufklärung. Suhrkamp, Frankfurt a. M., pp.12-32.

Ramos, A. (1988): Hacia una definición política del populismo latinoamericano, en: Revista Venezolana de Ciencia Política. No3, pp. 243-254.

Roberts, K. (2000): Populism and Democracy in Latin America. Ponencia presentada en el seminario: "Threats to Democracy in Latin America", Institute of International relations, University of British Columbia (Vancouver).

Savarino, F. (2006): Populismo: perspectivas europeas y latinoamericanas, en: Espiral, Vol XIII, pp. 77-94.

Schmitt, C. (1932): Der Begriff des Politischen. Duncker \& Humblot, Berlín.

Skolkay, A. (2000): Populism in Central Eastern Europe. IWM Working Paper No. 1/2000,Viena.

Taguieff, P.A. (1996): Las ciencias políticas frente al populismo: de un espejismo a un problema real. En: Picconne et al. (1996): Populismo posmoderno. Universidad Nacional de Quilmes, Buenos Aires.

Taggart, P (2003): Populism and the Pathology of Representative Politics, en: Meny, Yves y Surel,Yves (Ed.): Democracies and the populist challenge. Palgrave, Houndsmill y Nueva York.

Vilas, C. (1988): El populismo Latinoamericano: un enfoque estructural. En: Desarrollo Económico, Vol. 28, N¹11, pp. 323-352.

Walicki, A. (1969): Rusia., en: Gellner, Ernest y Ionescu, Ghita (compiladores). Populismo, sus significados y características nacionales. Amorrortu Editores, 1970, pp. 81-120.

Werz, N (2003): Alte und neue Populisten in Lateinamerika, en:Werz, N. (Ed.): Populismus. Populisten in Übersee und Europa.VS Verlag, Wiesbaden. 
Weyland, K. (2001) Clarifying a Contested Concept: Populism in the study of Latin American Politics. En: Comparative Politics, Vol. 34. N¹, pp. 1-22.

Weyland, K. (2003): Neopopulism and Neoliberalism in Latin America: How Much Affinity? Paper for Panel on Neopopulism in Latin America: Conceptual and Theorical Issues. XXIV International Congress, Latin American Studies Association. Dallas.

Worsley, P. (1969): El concepto de populismo. En: Gellner, Ernest y Ionescu, Ghita (Ed.): Populismo, sus significados y características nacionales. Amorrortu Editores, Buenos Aires, pp. 258-304. 